\title{
Strobe Rearing Reduces Direction Selectivity in Area 17 by Altering Spatiotemporal Receptive-Field Structure
}

\author{
ALLEN L. HUMPHREY AND ALAN B. SAUL \\ Department of Neurobiology, University of Pittsburgh School of Medicine, Pittsburgh, Pennsylvania 15261
}

\begin{abstract}
Humphrey, Allen L. and Alan B. Saul. Strobe rearing reduces direction selectivity in area 17 by altering spatiotemporal receptive-field structure. J. Neurophysiol. 80: 2991-3004, 1998. Direction selectivity in simple cells of cat area 17 is linked to spatiotemporal (S-T) receptivefield structure. S-T inseparable receptive fields display gradients of response timing across the receptive field that confer a preferred direction of motion. Receptive fields that are not direction selective lack gradients; they are S-T separable, displaying uniform timing across the field. Here we further examine this link using a developmental paradigm that disrupts direction selectivity. Cats were reared from birth to $8 \mathrm{mo}$ of age in 8-Hz stroboscopic illumination. Direction selectivity in simple cells was then measured using gratings drifting at different temporal frequencies $(0.25-16 \mathrm{~Hz})$. S-T structure was assessed using stationary bars presented at different receptive-field positions, with bar luminance being modulated sinusoidally at different temporal frequencies. For each cell, plots of response phase versus bar position were fit by lines to characterize S-T inseparability at each temporal frequency. Strobe rearing produced a profound loss of direction selectivity at all temporal frequencies; only $10 \%$ of cells were selective compared with $80 \%$ in normal cats. The few remaining directional cells were selective over a narrower than normal range of temporal frequencies and exhibited weaker than normal direction selectivity. Importantly, the directional loss was accompanied by a virtual elimination of S-T inseparability. Nearly all cells were S-T separable, like nondirectional cells in normal cats. The loss was clearest in layer 4. Normally, inseparability is greatest there, and it correlates well $(r=0.77)$ with direction selectivity; strobe rearing reduced inseparability and direction selectivity to very low values. The few remaining directional cells were inseparable. In layer 6 of normal cats, most direction-selective cells are only weakly inseparable, and there is no consistent relationship between the two measures. However, after strobe rearing, even the weak inseparability was eliminated along with direction selectivity. The correlated changes in S-T structure and direction selectivity were confirmed using conventional linear predictions of directional tuning based on responses to counterphasing bars and white noise stimuli. The developmental changes were permanent, being observed up to $12 \mathrm{yr}$ after strobe rearing. The deficits were remarkably specific; strobe rearing did not affect spatial receptive-field structure, orientation selectivity, spatial or temporal frequency tuning, or general responsiveness to visual stimuli. These results provide further support for a critical role of S-T structure in determining direction selectivity in simple cells. Strobe rearing eliminates directional tuning by altering the timing of responses within the receptive field.
\end{abstract}

\section{INTRODUCTION}

Direction selectivity is an important property of neurons in primary visual cortex. In area 17 of cats, $\sim 80 \%$ of cells in all layers are direction selective, responding strongly to

The costs of publication of this article were defrayed in part by the payment of page charges. The article must therefore be hereby marked "advertisement" in accordance with 18 U.S.C. Section 1734 solely to indicate this fact. a stimulus moving in one direction across their receptive field and weakly or not at all to movement in the opposite direction (Hubel and Wiesel 1962). A variety of mechanisms has been proposed to account for this tuning (Douglas and Martin 1991; Eysel 1992; Hubel and Wiesel 1962; Sillito 1977), but the precise substrates remain a matter of debate. An important insight, initially made by Movshon et al. (1978) and extended by others (Albrecht and Geisler 1991; McLean and Palmer 1989; Reid et al. 1987), is that direction selectivity in simple cells is linked to the spatiotemporal (S-T) structure of the receptive field. When tested with stationary stimuli, many direction-selective cells display S-T inseparable structure, in which response timing changes progressively from one position to the next across the receptive field. This organization produces a space-time orientation to the receptive field that confers a preferred direction of motion by virtue of greater response summation to one direction than to the other (Jagadeesh et al. 1997; McLean et al. 1994; Reid et al. 1991). In contrast, simple cells that lack directional tuning are all S-T separable. Their receptive fields are not oriented in space-time (McLean et al. 1994), hence motion in either direction evokes similar responses.

Rearing kittens in 8-Hz stroboscopic illumination leads to a profound loss of direction selectivity in cortex (Cynader and Chernenko 1976) and to behavioral deficits in directional discrimination (Pasternak et al. 1985; Pasternak and Leinen 1986). The mechanisms underlying the directional loss have never been explored. Given the normal involvement of S-T structure in direction selectivity, we wondered whether strobe rearing might produce its effect by altering that structure, perhaps by eliminating S-T inseparability. Finding such a change would not only reveal how strobe rearing acts on cortex, but it would provide further support for the spatiotemporal model of directional tuning. Alternatively, S-T structure might be normal after strobe rearing, which would indicate that the directional loss depends on other mechanisms. Inhibition evoked by motion in the nonpreferred direction has been reported to be essential for direction selectivity (Eysel 1992; Maex and Orban 1996; Sillito 1984; Suarez et al. 1995). One type of inhibition proposed (Sato et al. 1995) is that in which response thresholds are tonically raised so as to suppress weak activity. Such inhibition, however, would not be expected to impact response timing. Thus a strobe-induced loss of tonic inhibition would not affect S-T structure.

In this study we examined the impact of strobe rearing on S-T structure in simple cells. Structure was assessed using single, stationary bars placed at different receptive-field positions to generate maps of response timing. S-T inseparability 
was then quantified and compared with directional tuning. In normal cats, the relationship between these two parameters varies across layers (Murthy et al. 1998). In layer 4, most direction-selective cells have inseparable receptive fields, and the degree of inseparability correlates well with their directional tuning. In layer 6, inseparability is much weaker and poorly related to tuning. In the present study we were careful to distinguish these two layers.

We will show that the strobe-induced loss of direction selectivity reflects clear and consistent changes in S-T structure. In layer 4, S-T inseparability is eliminated; receptive fields become $\mathrm{S}-\mathrm{T}$ separable, like those of cells lacking direction selectivity in normal cats. Even in layer 6, the normally weak inseparability is reduced further by strobe rearing. Thus a S-T receptive-field model can account for directional tuning in normal cats and the loss of that tuning following strobe rearing. In the companion paper (Humphrey et al. 1998) we explore the specific changes in response timings associated with the temporal reorganization of the receptive field and suggest a mechanism for how strobe rearing produces its effects. Portions of these results have been reported in abstract form (Humphrey and Saul 1995; Saul and Humphrey 1994).

\section{METHODS}

\section{Strobe and normal rearing}

Fourteen kittens were reared from birth to 8-9 mo of age in a normal colony room illuminated only by a strobe lamp (PS-31, Grass Instruments) operating at $8 \mathrm{~Hz}(10 \mu \mathrm{s} /$ flash $)$ for $12 \mathrm{~h} /$ day, interleaved with $12 \mathrm{~h}$ of darkness. Recording sessions commenced from $4 \mathrm{~h}$ to $21 \mathrm{mo}$ after their removal from the strobe room. Two additional kittens were reared under virtually identical conditions by Dr. Tatiana Pasternak at the University of Rochester, and we recorded from them at $12 \mathrm{yr}$ of age. No differences were observed among animals in directional tuning or receptive-field structure, so data from all ages are combined. For comparison, data from five normally reared cats were collected under conditions identical to those used for testing the strobe animals.

\section{General procedures}

Methods were similar to those previously described (Saul and Humphrey 1990, 1992a). Animals were anesthetized using halothane in $70 \%$ nitrous oxide- $30 \%$ oxygen; halothane levels were $4 \%, 1.0-1.5 \%$, and $0.2-1.0 \%$, respectively, during induction, surgery, and recording. Heart rate, expired $\mathrm{CO}_{2}$, mean arterial blood pressure, and the raw and Fourier analyzed cortical electroencephalogram (EEG) were monitored throughout the experiment. Anesthetic was adjusted to maintain the dominant frequencies of the EEG below $4 \mathrm{~Hz}$. Paralysis was maintained by continuous infusion of gallamine triethiodide (Flaxedil; $5 \mathrm{mg} \cdot \mathrm{kg}^{-1} \cdot \mathrm{h}^{-1}$ ) and $d$-tubocurarine chloride $\left(0.35 \mathrm{mg} \cdot \mathrm{kg}^{-1} \cdot \mathrm{h}^{-1}\right)$, in $6 \mathrm{ml} / \mathrm{h}$ of $5 \%$ lactated Ringer solution. Additional Ringer solution was administered at $\sim 6 \mathrm{ml} / \mathrm{h}$ to maintain normal hydration and blood pressure. Wound margins and pressure points were infused with $2 \%$ lidocaine, and the head was supported by a skull attachment that allowed removal of the ear and eye bars.

Single neurons were recorded extracellularly with glass micropipettes filled with $10 \%$ horseradish peroxidase (HRP) in $0.2 \mathrm{M}$ $\mathrm{KCl}$ and tris (hydroxymethyl)-aminomethane buffer. These highimpedance (50-100 M $\Omega$ ) electrodes assured adequate sampling of small as well as large neurons (Humphrey and Weller 1988a,b). Each experiment was terminated by intravenously infusing a bolus of pentobarbital sodium (Nembutal), and the brain was perfused with aldehydes.

\section{Stimulus protocols}

Visual stimuli were presented on a Tektronix 608 monitor driven by a Picasso image synthesizer (Innisfree) with a $200-\mathrm{Hz}$ refresh rate, controlled by an LSI 11/73 computer. For all stimuli, mean luminance was $15 \mathrm{~cd} / \mathrm{m}^{2}$, and Rayleigh-Michelson contrast was $\sim 0.5$. Standard stimuli were used to assess the visual response properties of cortical cells (Saul and Humphrey 1992a,b).

ORIENTATION SELECTIVITY AND SPATIAL- AND TEMPORALFREQUENCY TUNING. Each cell's optimal orientation and tuning range were determined using drifting sinewave gratings of nearoptimal spatial and temporal frequency. The cell's spatial response properties were characterized next using sinewave gratings drifting in each direction at near-optimal temporal frequency and at spatial frequencies ranging over 3 octaves. Temporal response tuning and direction selectivity were examined using gratings of optimal spatial frequency drifting in opposite directions over a range of temporal frequencies from 0.25 to $16 \mathrm{~Hz}$. Each stimulus was randomly presented 5-10 times, at $4 \mathrm{~s}$ per trial, to generate a peristimulus time histogram (PSTH).

S-T RECEPTIVE-FIELD STRUCTURE. Two methods were used to evaluate receptive-field structure in most cells. In the first an optimally oriented, stationary, elongated $\left(5-8^{\circ}\right)$ bar undergoing sinusoidal luminance modulation was used to generate a form of lineweighting function (LWF). The bar was placed in 8 or 16 positions spanning the receptive field and adjacent regions, and luminance was modulated at five to seven temporal frequencies, usually $0.5-$ $6 \mathrm{~Hz}$. Bar width was typically $0.2-0.3^{\circ}$. Each unique temporal frequency/bar position pair was presented randomly for $4 \mathrm{~s}$, with 5-10 iterations of each pair, to generate a PSTH.

In the second method, hereafter referred to as sparse noise, a briefly flashed stimulus was presented (Jones and Palmer 1987). An elongated, narrow bar was randomly placed sequentially in 32 positions spanning the receptive field and adjacent regions. Bright and dark bars were used, at contrasts of 0.8 relative to background. Stimulus duration was $40 \mathrm{~ms}$. Stimulus order was rerandomized for each trial. Ten to 35 independent trials, $32 \mathrm{~s}$ each, generated separate maps of responses to the bright and dark bars.

\section{Data analysis}

Action potentials were collected at 1-ms resolution and histograms constructed using $\sim 5$ - to 8 -ms binwidths. Responses to sinusoidally varying stimuli were analyzed by converting spike counts to firing frequency at each point in the stimulus cycle and Fourier analyzing each resulting PSTH; means \pm SE of the fundamental response amplitude and phase were calculated (Saul and Humphrey 1992a). Standard errors of phase were computed in the complex plane, with deviations weighted by the amplitudes (Saul and Humphrey 1992a). Response phase was expressed in cycles (cyc). At low temporal frequencies 0.0 cyc corresponds to a response whose phase coincides with the maximal luminance, and 0.5 cyc reflects a response in register with the minimum luminance.

AMPLITUDE TUNING. For measuring spatial- and temporal-frequency tuning, curves of response amplitude versus frequency were fit by a difference of Gaussians function (Saul and Humphrey 1990). Resolution frequency was taken as the frequency above optimum that elicited $10 \%$ of maximal response. Curves of response versus stimulus orientation were fit by a Gaussian function, with half-width at $1 / e$ of the curve being the measure of orientation tuning.

DIRECTION SELECTIVITY. At each temporal frequency, direction selectivity was computed as the Rayleigh-Michelson (R-M) ratio, $R-M=(P D-N P D) /(P D+N P D)$, where $P D$ and $N P D$ are 
TABLE 1. Response properties of simple cells

\begin{tabular}{|c|c|c|c|c|c|c|c|c|}
\hline Normal & $\begin{array}{c}6 \pm 3(77) \\
{[0-14]}\end{array}$ & $\begin{array}{c}26 \pm 14(78) \\
{[8-68]}\end{array}$ & $\begin{array}{c}0.5 \pm 0.3(69) \\
{[0.1-1.6]}\end{array}$ & $\begin{array}{c}1.1 \pm 0.6(67) \\
{[0.3-3.2]}\end{array}$ & $\begin{array}{c}2.4 \pm 1.4(71) \\
{[0.3-7.3]}\end{array}$ & $\begin{array}{c}11.6 \pm 4.7(70) \\
{[3-31]}\end{array}$ & $\begin{array}{c}5.32 \pm 0.69(68) \\
{[3.0-7.0]}\end{array}$ & $\begin{array}{c}3.32 \pm 1.13(56) \\
{[1.0-5.0]}\end{array}$ \\
\hline Strobe & $\begin{array}{c}5 \pm 3(119) \\
{[0-13]}\end{array}$ & $\begin{array}{c}23 \pm 18(119) \\
{[6-123]}\end{array}$ & $\begin{array}{c}0.6 \pm 0.4(102) \\
{[0.3-1.8]}\end{array}$ & $\begin{array}{c}1.3 \pm 0.6(100) \\
{[0.3-2.8]}\end{array}$ & $\begin{array}{c}2.1 \pm 1.6(115) \\
{[0.1-11.7]}\end{array}$ & $\begin{array}{c}10.2 \pm 4.8(112) \\
{[2-31]}\end{array}$ & $\begin{array}{c}5.10 \pm 0.70(109) \\
{[3.0-6.5]}\end{array}$ & $\begin{array}{c}2.04 \pm 0.91(14) \\
{[1.0-4.0]}\end{array}$ \\
\hline Significance & NS & NS & NS & NS & NS & NS & NS & $P<0.001$ \\
\hline
\end{tabular}

Values are means $\pm \mathrm{SD}$ with number of cells in parentheses and range in brackets. $\mathrm{OS}_{\mathrm{wid}}$, half-width at $1 / e$ of the height of the orientation tuning curve; $\mathrm{SF}_{\mathrm{opt}}$ and $\mathrm{TF}_{\mathrm{opt}}$, optimal spatial and temporal frequency, respectively; $\mathrm{SF}_{\mathrm{res}}$ and $\mathrm{TF}_{\mathrm{res}}$, spatial and temporal frequency giving $10 \%$ of maximal response; $\mathrm{TF}_{\mathrm{oct}}$, octaves of temporal frequency over which cells responded to drifting gratings, irrespective of direction; $\mathrm{DS}_{\mathrm{oct}}$, octaves of temporal frequency over which direction-selective cells displayed directional tuning; NS, not significant.

response amplitudes to the preferred and nonpreferred directions of motion, respectively. For each temporal frequency the two directions were compared using the $t$-statistic (Saul and Humphrey 1992b). Our criterion for direction selectivity was an R-M ratio $\geq 0.33$ and a $t$-score $>2$, reflecting a response at least twice as great in the preferred than nonpreferred direction, that differed at or below the 0.05 level of significance.

To compare directional tuning among cells, each neuron's R-M ratio at 1 and $2 \mathrm{~Hz}$ was computed, and the mean value was used as a directional index (DI). This provided a representative summary of direction selectivity because 1 ) most cells in both rearing groups responded well at 1 and $2 \mathrm{~Hz} ; 2$ ) in normal cats, direction selectivity is usually strong at these temporal frequencies (Saul and Humphrey 1992b); and 3) strobe rearing did not affect temporal frequency tuning (Table 1$)$. For a few $(<5 \%)$ cells in each group whose directional tuning and/or optimal temporal frequency was shifted to much higher frequencies (e.g., $>4 \mathrm{~Hz}$ ), DIs were compiled at those higher frequencies that best reflected the directional tuning.

S-T RECEPTIVE-FIELD STRUCTURE. The line-weighting functions derived from counterphasing bars were used to quantify the S-T inseparability of each receptive field. In principle, the procedure was equivalent to comparing the fits of a line and a step function to the response phase versus bar position data for each tested temporal frequency. In practice, we compared the residuals $\left(R_{0}\right.$, $\left.R_{1}\right)$ of the fits for lines of zero slope $\left(L_{0}\right)$ and nonzero slope $\left(L_{1}\right)$. A separable receptive field has constant phase across space, except for half-cycle jumps between ON and OFF zones. We therefore used phase values modulo a half cycle for fitting the constant phase line, $L_{0}$, to normalize ON and OFF responses. We compared a separable hypothesis where $L_{0}$ gives a good fit, and an inseparable hypothesis were $L_{1}$ fits better. The index of inseparability was $R_{0} /\left(R_{0}+R_{1}\right)$. A perfect fit with $L_{0}$ would give $R_{0}=0$ and $R_{1}>0$, and thus an inseparability value of 0 (i.e., complete separability). A perfect fit with $L_{1}$ would give $R_{0}>0$ and $R_{1}=0$, and a value of 1 (i.e., complete inseparability). For population comparisons, an Inseparability Index (II) was computed for each cell that reflected the average of its inseparability values at 1 and $2 \mathrm{~Hz}$ (or higher frequencies for some cells ).

Space-time maps also were derived by reverse correlating a cell's responses to the one-dimensional (1-D) sparse noise (DeAngelis et al. 1993a,b; Jones and Palmer 1987). Spike trains were correlated with the position and contrast of the bars preceding each spike. Temporal resolution of the maps was generally $10 \mathrm{~ms}$, with durations from 320 to $2,560 \mathrm{~ms}$, depending on the type of analysis desired. Responses to bright and dark bars were compiled into separate maps, which were subtracted to yield a difference map of the net excitatory response to the two contrasts. ON and OFF excitatory regions are indicated, respectively, by continuous and dashed contours, with 10-16 levels between the maximum positive and negative responses.
LINEAR PREDICTIONS OF DIRECTION SELECTIVITY. Our primary measure of S-T structure (the II) is based on the distribution of response phase across the receptive field. We recently showed (Murthy et al. 1998) that a phase-based measure predicts directional tuning better than conventional linear predictions. The latter use response phase and amplitude, but amplitude nonlinearities produce underestimates of the linear component of direction selectivity. Nevertheless, to allow comparison of our data with those of other studies, we also used conventional linear predictions as follows. Response versus position data from the line-weighting functions were Fourier transformed to estimate the response amplitude to opposite directions of motion as a function of spatial frequency for each temporal frequency. The sparse-noise maps were similarly analyzed by 2-D transformation to the frequency domain. Predicted direction selectivity was then computed for each cell at its optimal spatial frequency and at a range of temporal frequencies (DeAngelis et al. 1993a). To compare these predictions to actual DIs, the mean predicted direction selectivity at 1 and $2 \mathrm{~Hz}$ (or higher for some cells) was computed for each cell.

\section{Cell identification}

Simple and complex cells were distinguished based on the segregation of ON and OFF zones in hand plots (Hubel and Wiesel 1962), line-weighting functions (Movshon et al. 1978; Saul and Humphrey 1992a), and/or sparse-noise tests (Jones and Palmer 1987), and on the degree of response modulation to drifting gratings (Skottun et al. 1991). Cells with only one zone were considered to be simple if they produced well-modulated responses to drifting gratings of high spatial frequency. Cells were deemed unclassified if their receptive-field structure was unclear.

\section{Histology}

Electrode tracks were reconstructed in Nissl-stained sections with the aid of HRP deposits applied extracellularly at the end of each penetration (Saul and Humphrey 1992a). Laminar borders were identified using standard criteria (Humphrey et al. 1985; O'Leary 1941), and cell recording locations were assigned accordingly.

\section{Statistics}

All statistical comparisons of means were done using the $t$-test.

\section{RES ULTS}

Directional selectivity was examined quantitatively in 128 and 81 simple cells, respectively, in strobe-reared and normal cats. S-T receptive-field structure was analyzed in about half of these cells. We first summarize the strobe-induced loss of direction selectivity and then document its impact on the 

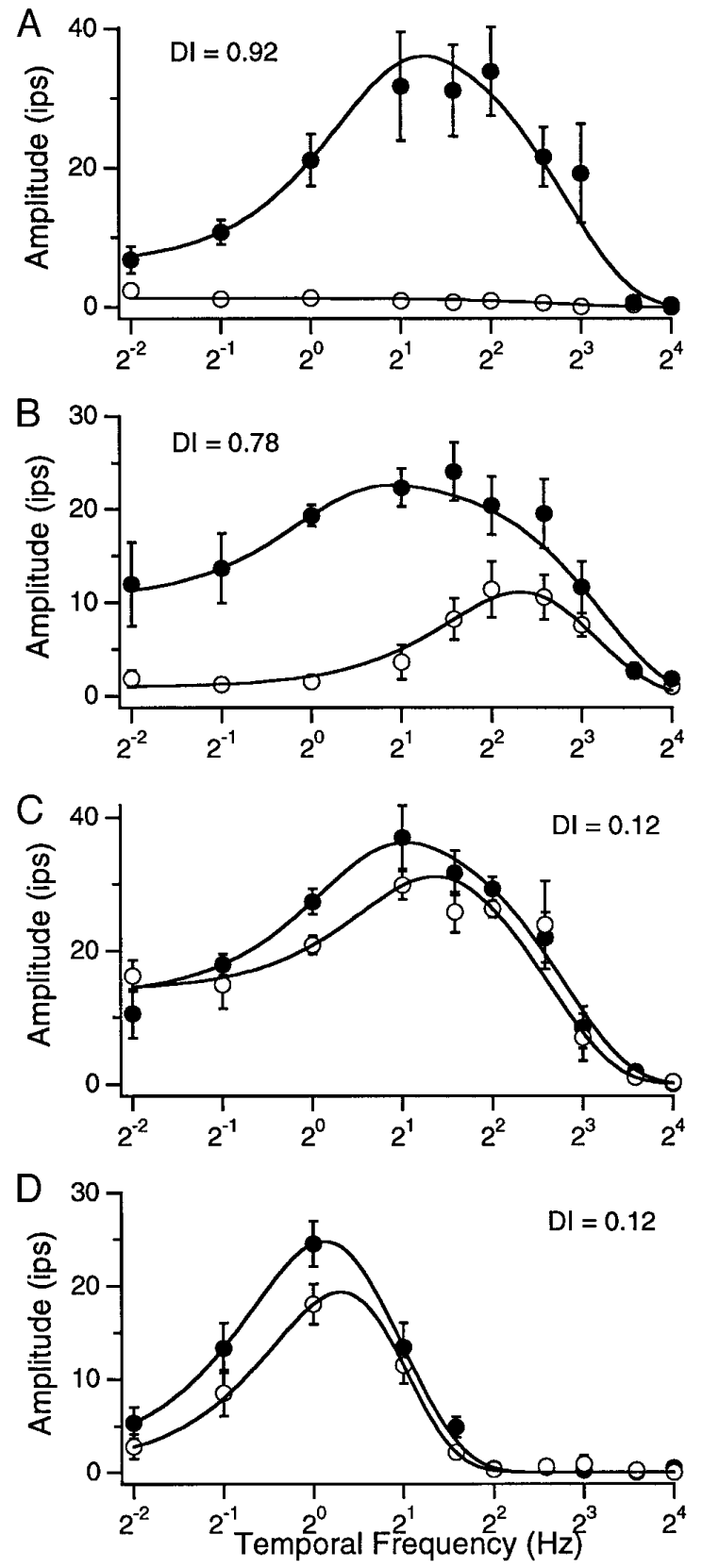

FIG. 1. Typical examples of temporal frequency tuning curves for cells in normal $(A$ and $B)$ and strobe-reared $(C$ and $D)$ cats. Open and filled circles represent average fundamental response amplitudes $( \pm \mathrm{SE})$ to sinewave gratings moving in opposite directions. Each set of responses is fit by a difference-of-Gaussians function. The directional index (DI), reflecting the average tuning at 1 and $2 \mathrm{~Hz}$, is indicated for each cell.

receptive fields of typical cells. We then present population analyses that reveal that the directional loss reflects a virtual elimination of S-T inseparability. Finally, we show that strobe rearing only impacts directional tuning, leaving other response properties normal.

\section{Direction selectivity}

Figure $1, A$ and $B$, illustrates directional tuning as a function of temporal frequency for two simple cells in normal cats. The cell in $A$ was highly selective at most frequencies, giving virtually no response in the nonpreferred direction. Its DI was 0.92 . The cell in $B$ responded over a roughly similar range of temporal frequencies but was direction selective only below 4 $\mathrm{Hz}$ (DI = 0.78). Although simple cells differ in the details of their directional and temporal frequency tuning (Saul and Humphrey 1992b), these profiles are representative of most neurons in area 17 of normal cats.

Temporal frequency tuning curves for two cells in strobereared cats are shown in Fig. 1, $C$ and $D$. The cells responded vigorously over ranges of temporal frequencies similar to those in normal cats but were not significantly direction selective at any frequency ( $\mathrm{R}-\mathrm{M}$ ratios $\leq 0.12$ ). These tuning curves are representative of nearly all cells in strobe-reared cats.

The frequency distribution of DIs observed among all simple cells in normal cats is summarized in Fig. $2 A$. A full range of directional tuning was observed, but $80 \%$ of the cells were selective, having DIs $>0.33$ and $t$-values $>2.0$. In comparison, only $11 \%(14)$ of the cells in strobe-reared cats were selective (Fig. $2 B$ ); the majority had lost directional tuning at all temporal frequencies. The mean DI was reduced by strobe rearing from a norm of 0.65 to 0.15 .

Interestingly, the few direction-selective cells remaining in strobe-reared cats were abnormal in two regards. First, they were selective over a narrower than normal range of temporal frequencies, the average range being 2.0 octaves compared with a norm of 3.3 octaves (Table 1). This difference was
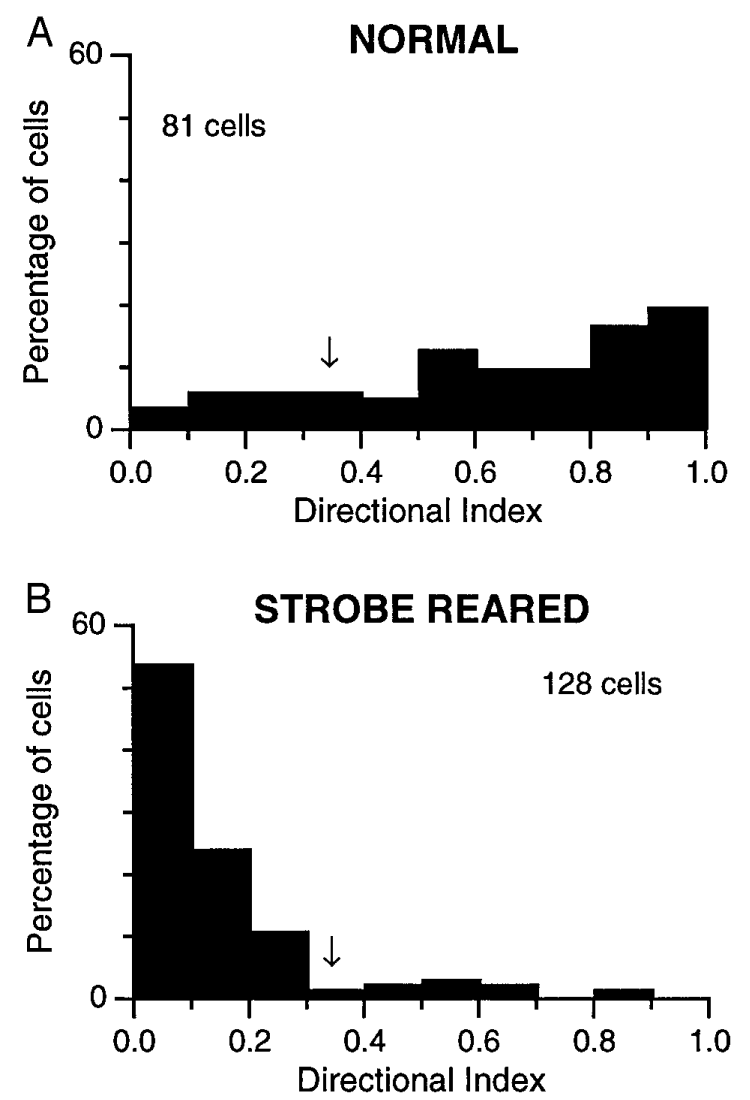

FIG. 2. Frequency distributions of DIs for simple cells in normal $(A)$ and strobe-reared $(B)$ cats. The mean DI in $A$ and $B$ is 0.65 and 0.15 , respectively; the difference is significant $(P<0.001)$. Strobe rearing reduced the frequency of direction-selective cells to $\sim 10 \%$ from a norm of $80 \%$. Arrows indicate a DI of 0.33 , reflecting a response twice as great in the preferred than nonpreferred direction. 
statistically significant $(P<0.001)$. Second, the directionally tuned cells were less selective than their normal counterparts. The mean DI of such cells in strobe-reared and normal cats was 0.59 and 0.74 , respectively, and this difference also was significant $(P<0.001)$. Overall, these data suggest that the development of directional tuning among all simple cells in area 17 was affected by strobe rearing.

\section{$S$-T receptive-field structure and direction selectivity: individual cells}

Spatiotemporal structure was measured primarily from line-weighting functions obtained with counterphasing bars. For about one-half of the cells, S-T maps also were generated using sparse-noise stimulation. The latter maps were used to confirm qualitatively the S-T structure revealed in the LWFs and to make linear predictions of directional tuning. We first provide examples of S-T structures in normal cats and then show typical examples from strobe-reared animals.

NORMAL CATS. S-T maps for a direction-selective cell recorded in layer 4B are shown in Fig. 3A. Each map plots the average response to a bar presented at six positions in the receptive field. Stimulus luminance was modulated at the indicated temporal frequencies, and a vigorous response was obtained at most positions. Hand plotting of the receptive field revealed an ON zone flanked by two OFF zones (see inset). The LWFs confirmed this spatial organization. For example, the map obtained at $1 \mathrm{~Hz}$ shows the ON zone at positions $-0.4^{\circ}$ and $-0.1^{\circ}$ discharging to increasing stimulus luminance, and the OFF flanks at positions $-1.0^{\circ}$, and $+0.1^{\circ}$ to $+0.4^{\circ}$ firing with deceasing luminance.

Figure $3 \mathrm{~A}$ also reveals that response timing varied systematically within and between each zone to produce a gradual temporal progression across the receptive field. This is summarized in Fig. $3 B$, which plots the temporal phase of the fundamental response as a function of bar position for each temporal frequency. At frequencies below $4 \mathrm{~Hz}$, most adjacent positions differed in response phase by a quarter cycle or less.

The timing progression in this receptive field produced a clear space-time orientation to each S-T map. To quantify orientation we calculated an Inseparability value, which reflected the organization of response phase across the receptive field ( see METHODS ); this was done for each temporal frequency. A purely inseparable receptive field, exhibiting a highly oriented S-T map due to uniformly small shifts in response phase across the receptive field, would have a value of 1.0. A purely separable receptive field, displaying constant timing within each zone and half-cycle jumps between them, would have a value of 0 . Inseparability values for the cell in Fig. 3 are given in parentheses in $B$; they range from 0.95 at $1 \mathrm{~Hz}$ to 0.27 at $4 \mathrm{~Hz}$. The receptive field was highly inseparable below $4 \mathrm{~Hz}$.

The changes in inseparability with temporal frequency paralleled the cell's directional tuning to drifting gratings (Fig. 3C). It was highly selective at drift frequencies below $4 \mathrm{~Hz}$; it remained responsive but less directionally tuned up to $8 \mathrm{~Hz}$. This temporal frequency-dependent tuning is typical of many cells in area 17 of normal cats (e.g., Fig. 1A) (Saul and Humphrey 1992b).

Sparse-noise stimulation confirmed the S-T structure of this cell's receptive field. Figure $3 D$ plots the cell's re- sponses in space-time coordinates; the contour lines in the difference map reveal the S-T extent of bright- and darkexcitatory regions. The regions closely matched those in the LWFs, although an additional, weak ON excitatory zone at approximately $-1.5^{\circ}$ also was revealed. All regions were highly oriented in space-time, as expected for an inseparable receptive field (DeAngelis et al. 1993a,b; McLean et al. 1994). Transformation of these data to the frequency domain yielded a predicted DI of 0.56 , about one-half that actually observed (0.98).

Spatiotemporal inseparability, like direction selectivity, varies across a continuum of values. The cell in Fig. 3 occupied one end of the inseparability continuum; the cell in Fig. 4 occupied the opposite end. This layer 6 cell responded equally well to both directions of motion over 5 octaves of temporal frequency (Fig. 4C). LWFs revealed an ON and an OFF zone (Fig. 4A). However, response timing across these zones was much more uniform than in the cell above. Plots of response phase versus position (Fig. $4 B$ ) showed that, at every temporal frequency tested, timing was roughly constant within each zone and differed by a half-cycle between zones. Thus inseparability values were low $(<0.2)$ at all frequencies. Sparse-noise stimulation confirmed the separable nature of the receptive field. Figure $4 D$ illustrates its nonoriented space-time plot, which yielded a predicted DI of 0.08 .

STROBE-REARED CATS. Strobe rearing had a striking effect on simple-cell receptive fields: virtually all were S-T separable. Results from a typical cell, recorded in layer 4B, are illustrated in Fig. 5. The cell responded well at all tested temporal frequencies but was not direction selective (Fig. $5 C$ ). Counterphasing bars revealed robustly responding ON and OFF zones; response timing was constant within each zone and differed by a half-cycle between them (Fig. 5, A and $B$ ). Consequently, all Inseparability values were uniformly low $(\leq 0.16)$. This basic spatiotemporal organization was confirmed by sparse-noise stimulation (Fig. $5 D$ ), which predicted no directional tuning.

A striking example of another layer 4 cell that lacked direction selectivity is illustrated in Fig. 6. The receptive field comprised five distinct zones and was quite separable, with half-cycle jumps between zones (Fig. $6, A$ and $B$ ). Inseparability values were quite low $(<0.17)$ at all temporal frequencies. The sparse-noise map (Fig. $6 C$ ) confirmed the spatial structure of the receptive field and the virtual absence of space-time orientation and predicted no directional tuning $(\mathrm{DI}=0.18)$.

The S-T maps from these two cells are highly representative of $>90 \%$ of those examined in strobe-reared cats. They differed strikingly from maps of direction-selective cells in normal animals, which usually displayed some degree of space-time orientation. On the other hand, the maps in strobe-reared animals were indistinguishable from those of cells in normal cats that were not direction selective.

\section{Relation between S-T inseparability and direction selectivity: population data}

INSEPARABILITY INDEX. Figure $7 A$ summarizes the frequency distribution of II for simple cells in normal cats. A full range of values was seen; the mean index was 0.39 and 

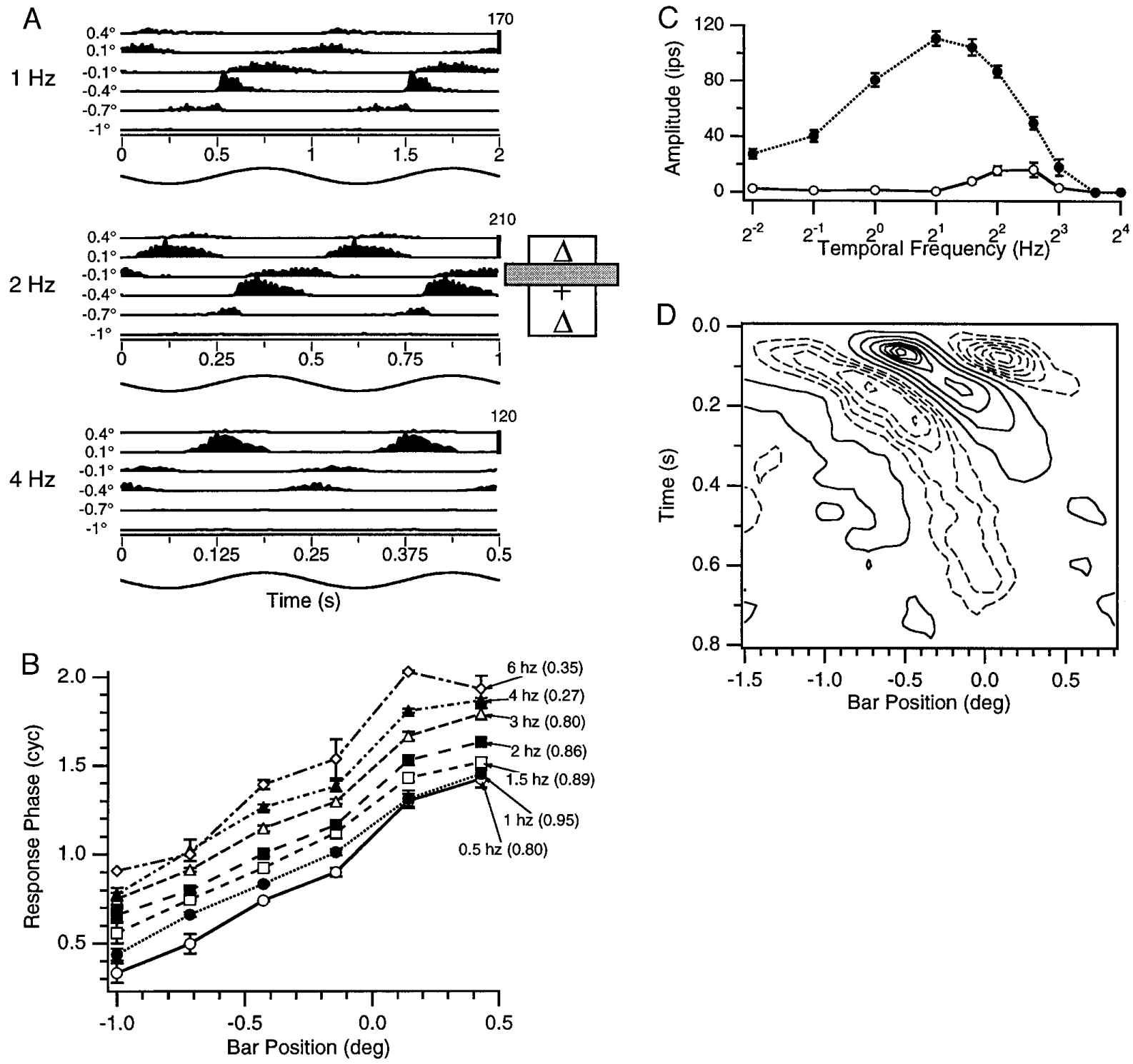

FIG. 3. Spatiotemporal (S-T) structure and directional tuning of a direction-selective simple cell in layer $4 \mathrm{~B}$ of a normal cat. $A$ : peristimulus time histograms (PSTHs) of responses to a stationary bar undergoing sinusoidal luminance modulation at 6 positions in the receptive field and 3 temporal frequencies. Two cycles of stimulation are shown for clarity, with the 2nd response in each PSTH being a duplicate of the 1st. Each set of PSTHs provides an S-T map of the receptive field at 1 temporal frequency; all maps reveal a highly S-T oriented field. The handplotted receptive-field and bar stimulus are shown to the right; bar width and field dimensions are scaled to the S-T map. The vertical scale bar and response scaling value (in impulses/s) are shown in the top right of each map. Values for receptive-field position reflect rounding. $B$ : mean $\pm \mathrm{SE} 1$ st harmonic response phase is plotted as a function of bar position for each temporal frequency tested. Note that the standard errors for many points are smaller than the symbols used to indicate phase. Phase values were adjusted by addition of integers to minimize the difference between adjacent positions and maintain increasing phase with temporal frequency. Each set of phase vs. position values was fit by lines (not illustrated; see METHODS ) to derive an Inseparability value, which is indicated in parentheses. $C$ : mean \pm SE fundamental response amplitude is plotted as a function of the temporal frequency of a grating drifting in opposite directions. The cell was highly direction selective up to $\sim 4 \mathrm{~Hz}(\mathrm{DI}=0.98)$. $D$ : space-time response profile obtained by the use of the sparsenoise method. Contours represent net excitatory responses to the bright (continuous lines) and dark (dashed lines) bars. The receptive field is highly oriented in space-time. For illustration, the contours in this and following figures were smoothed slightly using a narrow Gaussian filter.

$>70 \%$ of the cells had indexes $>0.2$. In comparison, indexes for strobe-reared cats were uniformly low (Fig. $7 B$ ); the mean index was 0.09 , and only $6 \%$ of cells had values $>0.2$. Qualitatively, indexes $<0.2$ reflected receptive fields that, under visual inspection, had little or no space-time orientation (e.g., Figs. 4 and 5). Thus nearly all receptive fields in strobe-reared cats were S-T nonoriented, whereas the majority in our normal sample were moderately to highly oriented. INSEPARABILITY VERSUS DIRECTIONAL INDEXES. In a recent study using counterphasing gratings to assess receptive-field structure, we reported that direction-selective cells in layer 4 generally had S-T well-oriented re- 

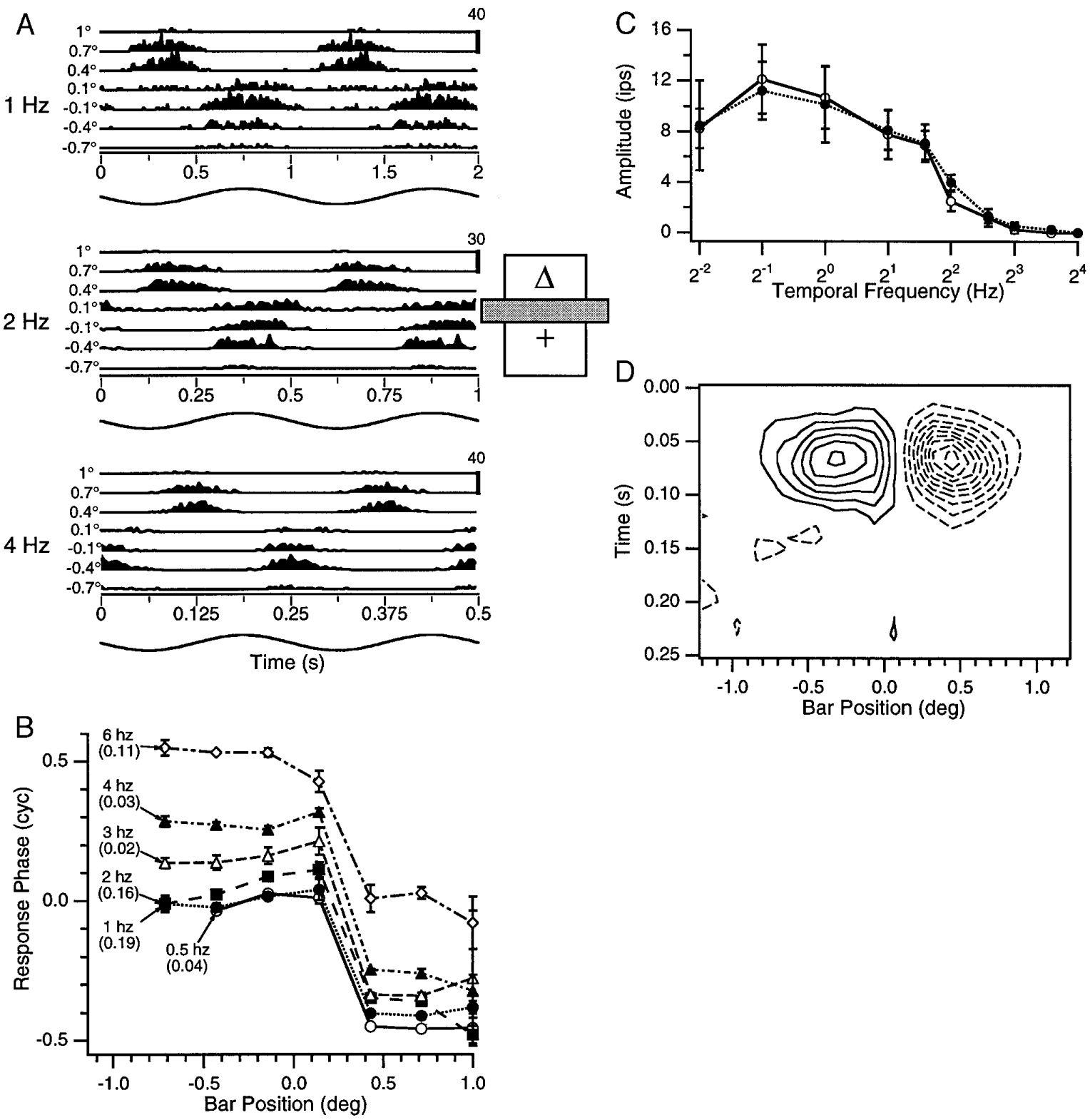

FIG. 4. S-T structure of a nondirectional cell in layer 6 of a normal cat. $A$ : receptive-field maps obtained using 3 temporal frequencies of luminance modulation. The receptive field was S-T separable. $B$ : phase vs. bar position plots for 6 temporal frequencies. Response phase was constant within each zone and differed by a half cycle between zones. $C$ : response amplitude vs. temporal frequency for a drifting grating reveals that the cell was insensitive to direction at all drift rates. $D$ : response profile obtained using sparse-noise stimulation revealed a nonoriented space-time map; predicted DI $=0.08$. All conventions are as in Fig. 3.

ceptive fields (Murthy et al. 1998). Cells in layer 6, in contrast, displayed uniformly low S-T orientation despite being direction selective. Here we reexamine these two laminar regions with regard to inseparability measured with the use of counterphasing bars.

Figure $8 \mathrm{~A}$ illustrates the relationship between direction selectivity and inseparability for cells in and adjacent to layer 4 in normal cats. Two points can be made. First, the sign of the Inseparability value indicates whether the slope of the response phase versus bar position data predicted the preferred direction accurately (positive values) or inaccurately (negative values). For virtually all cells, the predictions were correct. The exceptions here and elsewhere in the figure were cells that were not sensitive to stimulus direction (i.e., had DIs less than $\sim 0.2$ ). ${ }^{1}$ Second, a full range of values was observed for both measures in layer 4. Mean DI was 0.61 , mean II was 0.49 , and the two measures were well correlated $(r=0.77, P<0.001)$. Importantly, about onehalf of the data points fall near the dashed line of unity slope, indicating that the degree of directional tuning in each cell was accounted for by the degree of inseparability (i.e., the S-T organization of the receptive field). For most of the

\footnotetext{
${ }^{1}$ The nonzero and sometimes negative Inseparability values for nondirectional cells reflect noise in the inseparability measure, which can be slightly affected by excessive variations in response timings in some receptive fields.
} 

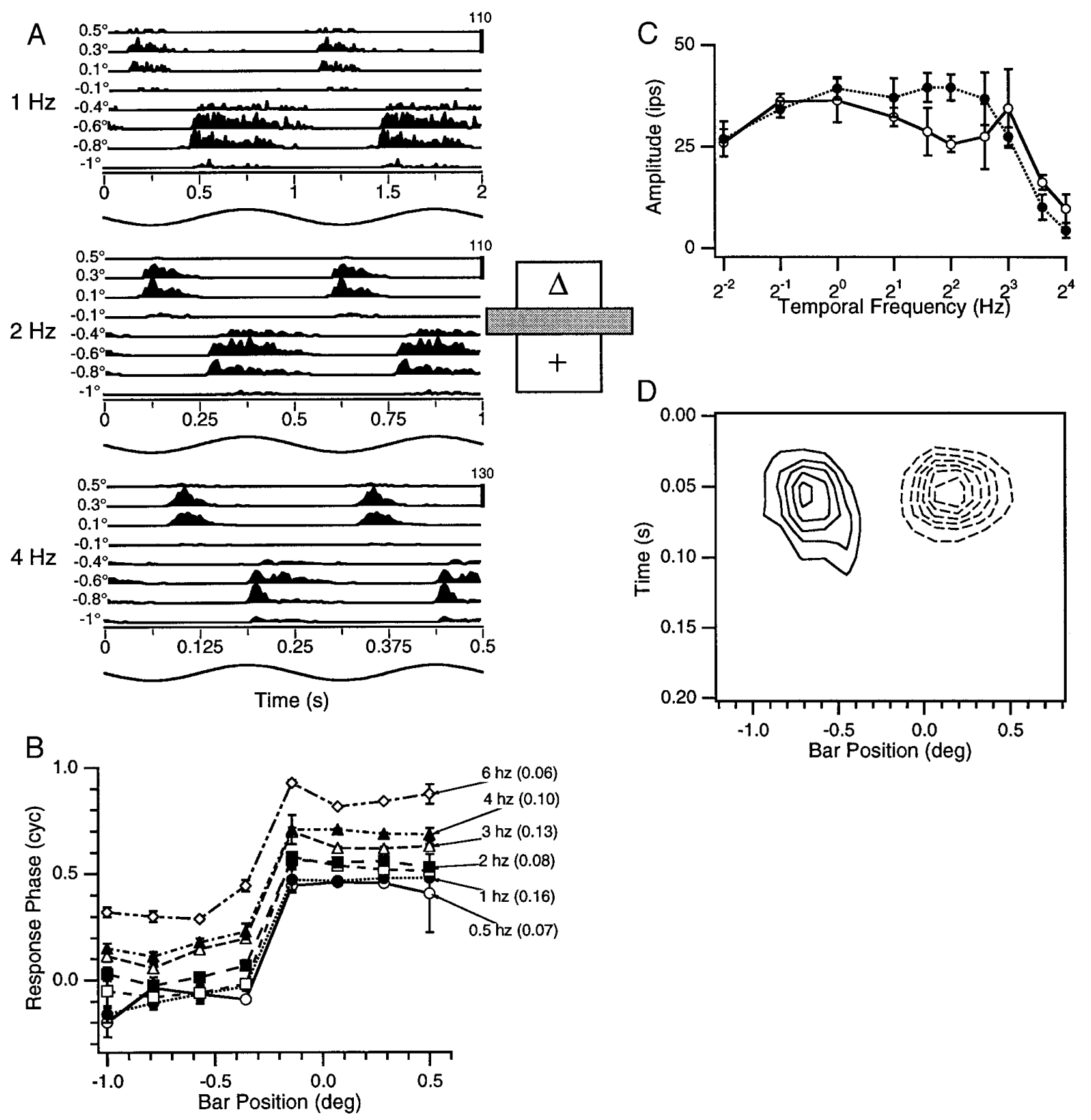

FIG. 5. S-T structure of a cell lacking direction selectivity in layer $4 \mathrm{~B}$ of a strobe-reared cat. $A$ : S-T maps show an inseparable receptive field. $B$ : phase vs. bar position plots for different temporal frequencies confirm the constancy of timing within the receptive field except for the half-cycle difference between ON and ofF zones. $C$ : amplitude vs. temporal frequency plots show that the cell was not direction selective ( $\mathrm{R}-\mathrm{M}$ ratio $\leq 0.22$ at all frequencies). $D$ : response profile obtained using sparse-noise stimulation confirmed the absence of space-time orientation. Predicted DI $=0.06$. Conventions are as in Fig. 3.

remaining cells, the II predicted directional tuning moderately well. These data confirm our earlier findings obtained using counterphasing gratings (Murthy et al. 1998).

Strobe rearing markedly affected both the direction and inseparability indexes in layer 4 (Fig. $8 B$ ). The mean DI was reduced to 0.15 , and the mean absolute value of II dropped to 0.12 . Both reductions from normal were statistically significant $(P<0.001)$. Note that the three remaining direction-selective cells in layer 4 had moderately inseparable receptive fields that predicted the preferred direction of motion and much of the directional tuning.

In normal cats, cells in and adjacent to layer 6 displayed a wide range of directional tuning; the mean DI for 24 such cells was 0.71 . Figure $8 C$ shows a subset of cells for which LWFs were also obtained. Compared with layer 4, the direction-selective cells displayed only weak inseparability, in agreement with our previous report (Murthy et al. 1998). The mean of the absolute values of IIs for the cells was 0.17 .

Strobe rearing not only reduced direction selectivity in layers 5 and $6($ mean DI $=0.14$ ) but it further reduced the already low inseparability values there (Fig. $8 D$ ). The mean absolute value of II was reduced to 0.07 , significantly lower than normal $(P<0.01)$. Note also that most of the remaining direction-selective cells had very low inseparability values. Curiously, one direction-selective cell was somewhat 

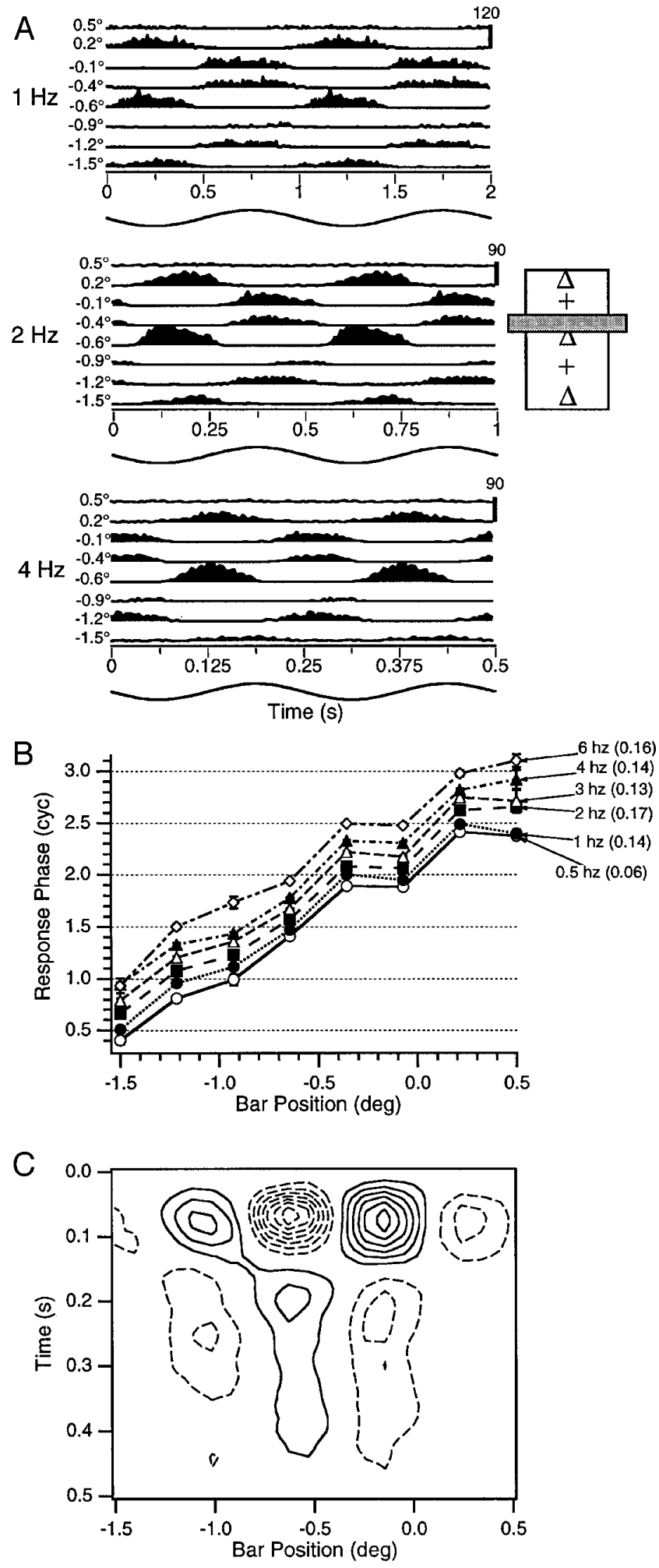

FIG. 6. S-T structure of a nondirectional receptive field in layer 4 of a strobe-reared cat. $A$ : S-T maps reveal 2 on and 3 off zones. $B$ : phase vs. bar position plots reveal half-cycle differences in response timing between each zone, yielding uniformly low inseparability values at all temporal frequencies. Grid lines are added to the ordinate to help visualize the halfcycle jumps. $C$ : response profile obtained with sparse noise. Except for a slightly oriented "bridge" at position $-0.8^{\circ}$, the receptive field was nonoriented in space-time. Predicted DI $=0.18$. Conventions as in Fig. 3.
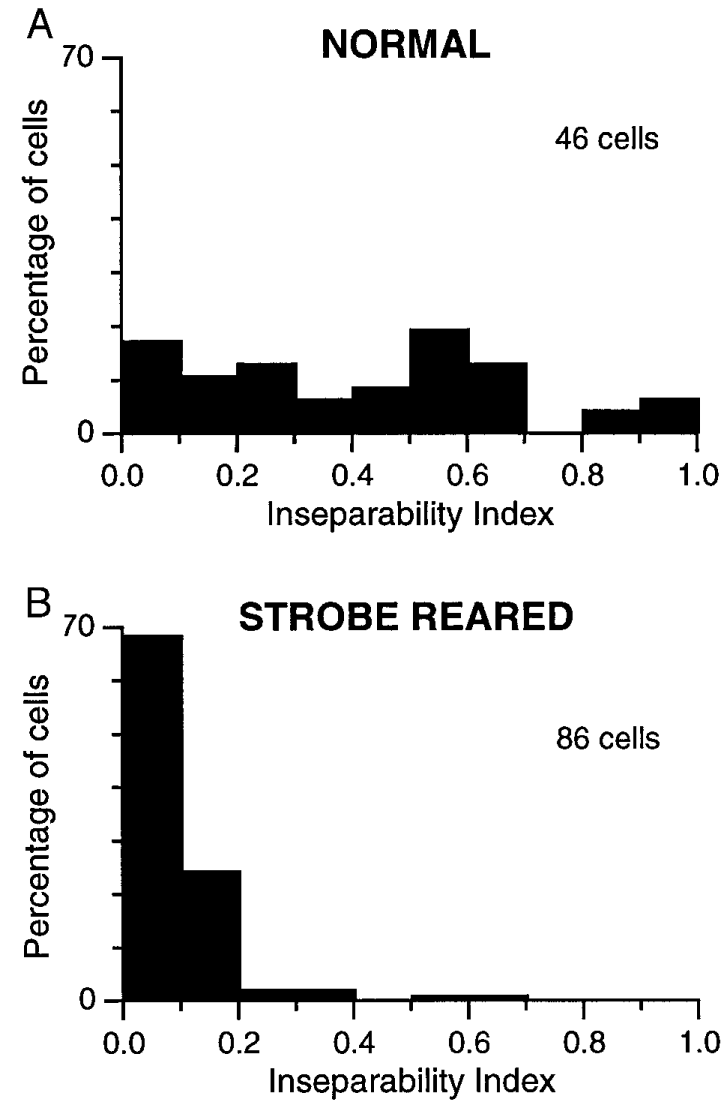

FIG. 7. Frequency distributions of Inseparability Indexes among simple cells in normal $(A)$ and strobe-reared $(B)$ cats. Strobe rearing eliminated virtually all inseparable receptive-field structure. The mean Index in $A$ and $B$ is 0.39 and 0.09 , respectively; the difference is significant $(P<0.001)$.

inseparable, but its S-T orientation incorrectly predicted the preferred direction of motion. Our sample of cells is too small to understand the significance of this.

In summary, results from normal cats confirm our previous finding that a strong relationship exists between S-T inseparability and direction selectivity among cells in and adjacent to layer 4 but not in the infragranular layers. In strobe-reared cats the loss of directional tuning in layer 4 can be largely accounted for by the clear loss of inseparable receptive-field structure. Even among layer 6 cells, the strobe-induced reduction of their normally weak inseparability implicates changes in S-T structure as a factor underlying the loss of their directional tuning. In the DISCUSSION we consider the significance of these laminar differences for directional mechanisms.

LINEAR PREDICTIONS. Fourier analyses of S-T maps were also employed to make linear predictions of directional tuning based on the distribution of response phase and amplitude in the receptive field (e.g., Albrecht and Geisler 1991; DeAngelis et al. 1993a,b). Evaluating first the maps obtained with counterphasing bars, Fig. $9 A$ plots DI versus predicted DI for simple cells in all layers of normal cats. Despite the full range of DIs, predicted selectivity was generally low ( mean absolute value $=0.23$ ). The correlation between the two measures was 0.5 , a value similar to that reported for simple cells in all layers by Reid et al. (1991) and Murthy et al. (1998) based on responses to gratings. Among strobe- 

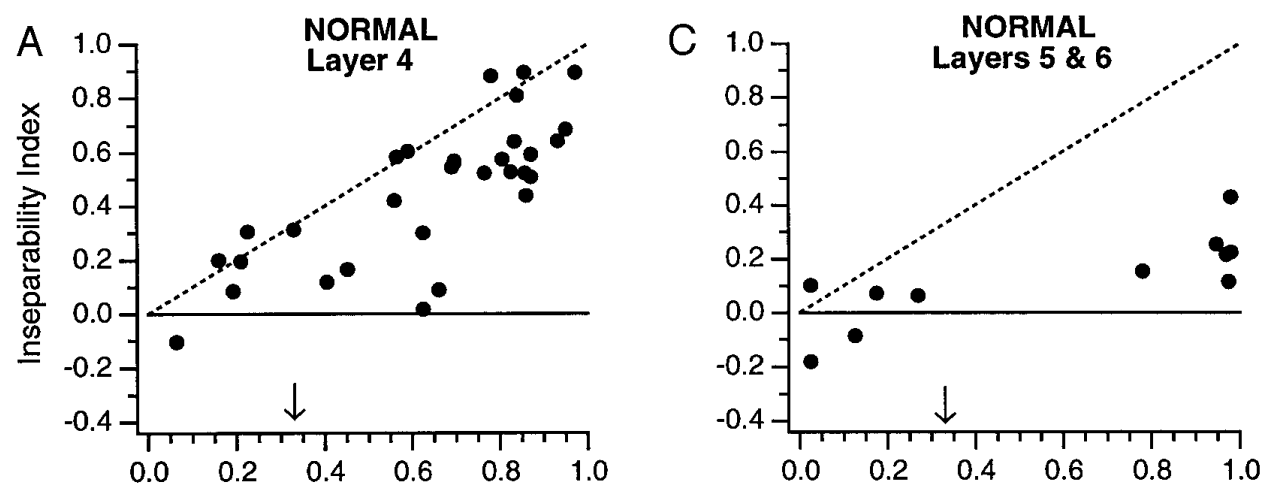

FIG. 8. Inseparability vs. direction selectivity among simple cells as a function of cortical layer. $A$ and $B$ : cells recorded in layer 4 and along its border zone with layers 3 and 5 . $C$ and $D$ : cells localized to layer 6 and the $5 / 6$ border; $D$ includes 6 cells recorded in layer $5 \mathrm{~B}$. $A$ : in layer 4 of normal cats, there was a wide range of inseparability and directional values, and the 2 indexes were well correlated $(r=$ 0.77 ; slope $=0.78)$. $B$ : strobe rearing eliminated direction selectivity and inseparability in nearly all layer 4 cells; among cells that were not direction selective, the 2 mea-
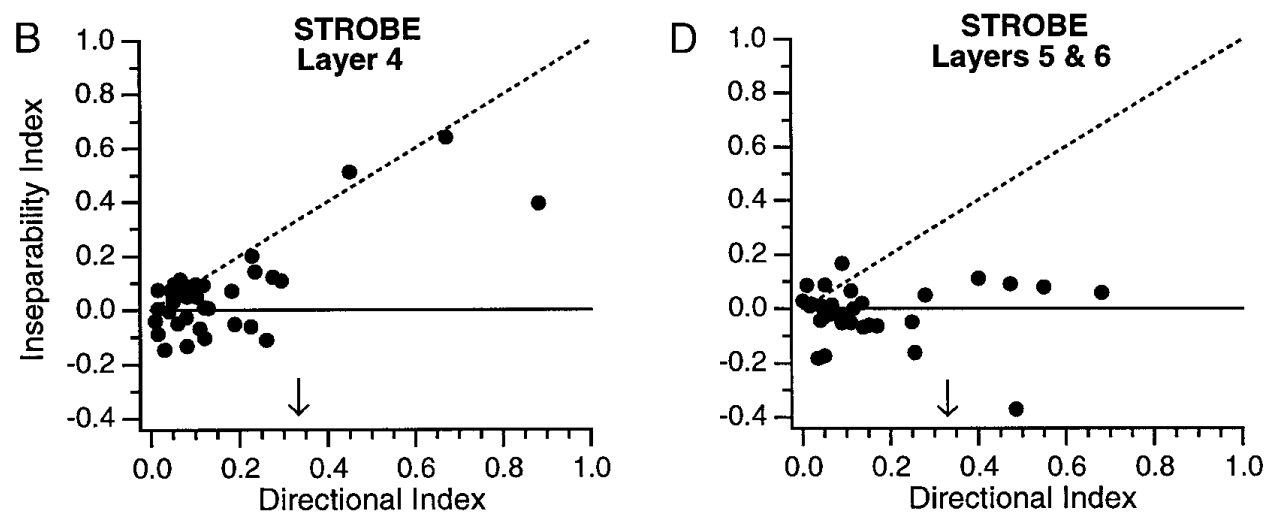
sures were uncorrelated. $C$ : in layer 6 of normal cats, there was a wide range of direction selectivities, but cells displayed low inseparability values $(r=0.79$, slope $=$ $0.30)$. $D$ : strobe rearing not only eliminated direction selectivity in the infragranular layers, it further reduced inseparability values there $(r=0)$. The sign of inseparability value indicates whether the S-T maps predicted the preferred direction of motion correctly (positive values) or incorrectly (negative values). Arrows indicate criterion breakpoint for direction selectivity.

reared cats (Fig. 9B) predicted direction selectivity was significantly lower than normal (mean absolute value $=0.07$, $P<0.001$ ), matching at least qualitatively the loss of directional tuning.

Figure $9 C$ plots for normal cats the relationship between DI and directional tuning predicted from sparse-noise maps. The average predicted selectivity was 0.29 , and the two measures were moderately correlated $(r=0.60)$. As above, there was a trend for larger predicted values to be associated with greater DIs, but the predictions generally underestimated actual tuning. This distribution is similar to that reported by DeAngelis et al. (1993b) and McLean et al. (1994), although the slope (0.30) is lower. Again in strobereared animals, however, the S-T maps predicted the loss of direction selectivity (Fig. 9D). The absolute value of the mean predicted selectivity was 0.09 , significantly lower than normal $(P<0.05)$.

It is clear by comparing Figs. 8 and 9 that the linear predictions are generally less well correlated with direction selectivity than the IIs. This is not surprising; we recently (Murthy et al. 1998) reviewed evidence (e.g., Albrecht and Geisler 1991; Movshon et al. 1978; Reid et al. 1991) that conventional "linear" predictions are confounded by static nonlinearities that result in underestimates of the linear component of direction selectivity. Response phase is not affected by such nonlinearities. Thus the II, which reflects only response phase, should better predict directional tuning.

\section{Strobe rearing does not affect other visual response properties}

In agreement with previous reports (Cynader and Chernenko 1976; Pasternak et al. 1985), we found that strobe rearing had a remarkably specific effect on simple cells, impacting only direction selectivity. Qualitatively, there were no deviations from normal in the sampling of simple, complex, and unclassifiable cells or in their optimal orientations and ocular dominance values. The numbers and widths of ON and OFF zones in simple-cell receptive fields were normal, and cells were quite visually responsive to stationary and moving stimuli. In fact, if one were not aware that most area 17 cells are normally direction selective, no deficits would have been noticed.

Table 1 compares response properties of simple cells measured in the two groups. No differences were observed in orientation selectivity $\left(\mathrm{OS}_{\text {wid }}\right)$ or in spatial frequency tuning $\left(\mathrm{SF}_{\mathrm{opt}}, \mathrm{SF}_{\mathrm{res}}\right)$. Cells in the two groups had similar optimal temporal frequencies $\left(\mathrm{TF}_{\mathrm{opt}}\right)$ and temporal frequency resolutions $\left(\mathrm{TF}_{\text {res }}\right)$ to drifting gratings, and they were responsive over similar ranges of temporal frequency $\left(\mathrm{TF}_{\mathrm{oct}}\right)$. The latter results are interesting because they show that viewing the world at an $8-\mathrm{Hz}$ sampling rate during the critical period did not shift temporal frequency tuning. As noted above, strobe rearing did reduce the range of temporal frequencies over which the few directionally tuned cells were selective $\left(\mathrm{DS}_{\mathrm{oct}}\right)$.

\section{I S C U S S I ON}

These experiments produced five major findings. 1) Strobe rearing reduced the proportions of direction-selective simple cells in area 17 from $\sim 80 \%$ to $\sim 10 \%$. 2) The loss of direction selectivity reflected the elimination of S-T inseparable receptive-field structure; all of the nondirectional cells had separable receptive fields. 3) The few directional cells 

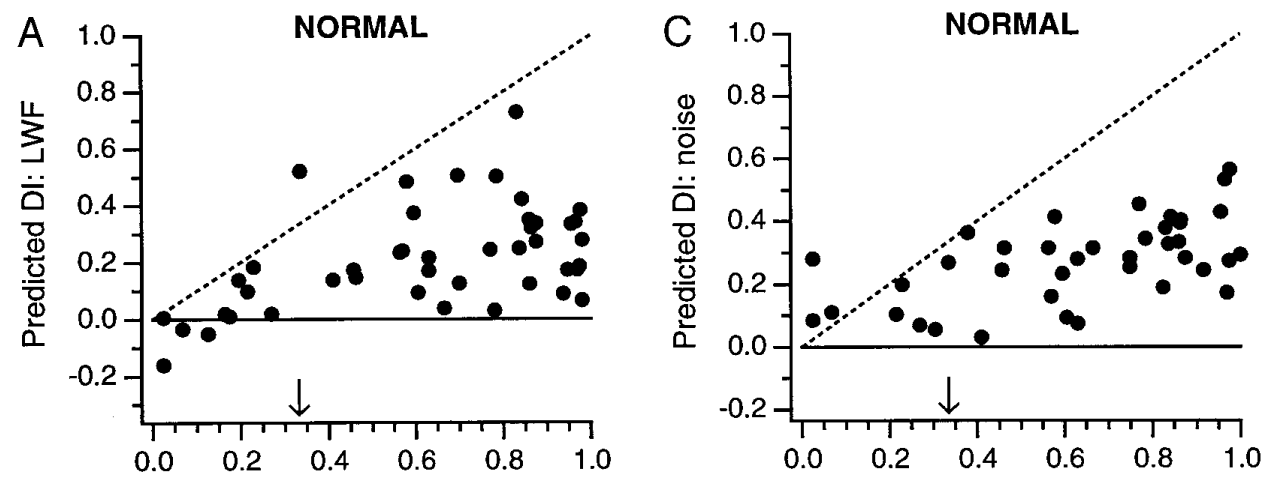

FIG. 9. Linearly predicted vs. actual directional tuning. Predictions were made at the same temporal frequencies as those used for calculating DI. $A$ and $B$ : predictions based on line-weighting functions. Strobe rearing reduced mean predicted selectivity from a norm of 0.23 to 0.07 (absolute values used). $C$ and $D$ : predictions based on maps obtained using sparse-noise stimulation. Absolute value of predicted direction selectivity was 0.29 and 0.09 , respectively, for normal and strobe-reared cats. The sign of the prediction value indicates whether the S-T maps predicted the preferred direction of motion correctly (positive values) or incorrectly (negative values). Arrows indicate criterion breakpoint for direction selectivity.
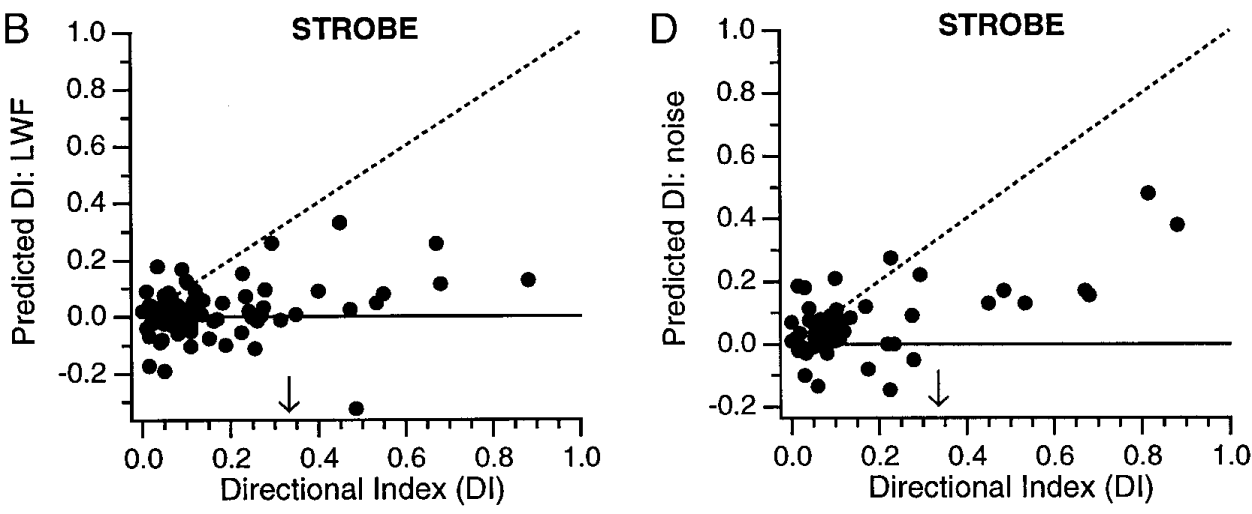

that existed after strobe rearing were selective over a narrower range of temporal frequencies, and exhibited weaker directional tuning, than normal. 4) Strobe rearing was highly selective; no changes in other measured receptive-field properties were seen. 5) The effects were permanent; the deficits were observed up to $12 \mathrm{yr}$ postdeprivation.

In the following sections we compare our results with those of previous studies, consider the findings in light of models for direction selectivity, and discuss the permanence of the changes observed.

\section{Relation to previous studies}

Cynader and Chernenko (1976) discovered that rearing cats in 8-Hz stroboscopic illumination reduced the number of direction-selective cells in area 17 from $\sim 80 \%$ to $\sim 10 \%$. Their stimuli were hand-held bars of light, and the deficit was associated with all cell classes. Pasternak et al. (1985) confirmed this and suggested that the directional loss might be greater among complex than simple cells. Our results from qualitative testing confirm the paucity of directional tuning in both cell classes following strobe rearing. Because our quantitative tests were restricted to simple cells, we cannot address the relative impact of the rearing on different classes. However, it is clear that simple cells were profoundly affected.

A number of developmental studies (Cremieux et al. 1987; Cynader et al. 1973; Kennedy and Orban 1983; Olson and Pettigrew 1974) have examined how lower rates of strobe stimulation, generally $0.5-2 \mathrm{~Hz}$, affect cortical organization. Such rates not only tend to reduce directional tuning but affect other response properties. On the whole, the changes include a reduction in the number of orientation- selective cells and/or a widening of orientation tuning (Cremieux et al. 1987; Cynader et al. 1973); abnormal spatial receptive-field structures (Cynader et al. 1973; Kennedy and Orban 1983); alterations in velocity tuning and its dependence on retinal eccentricity (Kennedy and Orban 1983); and reduction in the frequency of binocular receptive fields (Cremieux et al. 1987; Kennedy and Orban 1983; Olson and Pettigrew 1974). This broader range of deficits probably reflects illumination conditions that approach dark rearing. Rearing kittens in the dark results in widespread and profound degradative changes in cortical receptive-field structures and response selectivities (Sherman and Spear 1982). At low strobe rates the stimulation may be insufficient to sustain normal maturation of circuits underlying spatial and temporal structures. An $8-\mathrm{Hz}$ rate does suffice.

Our results also confirm the remarkable specificity of the strobe deficit, which seems to affect only direction selectivity. The lack of an 8-Hz strobe effect on spatial properties of cortical cells is perhaps not surprising. Spatial structures of the visual world associated with cages, other cats, toys, etc. provided a wealth of specific stimulus features such as contours with light/dark borders available at a variety of orientations and retinal eccentricities, and a wide range of spatial frequencies. Kittens appeared to interact normally with these stimuli. The visual information was thus sufficient to allow normal maturation of spatial receptive-field structures, a full range of preferred stimulus orientations and accompanying orientation tuning, and normal spatial frequency tuning.

Reasons for the lack of a strobe effect on temporal frequency tuning are less obvious. One might have expected a shift in optimal temporal frequency and/or temporal resolution following 8 mo of strobe stimulation, but this was not 
the case ( see also Pasternak et al. 1985). We note in the companion paper (Humphrey et al. 1998) that cells in the lateral geniculate nucleus (LGN) of strobe-reared cats also are normal in their frequency tuning. In normal cats, cells in area 17 tend to have lower temporal resolution than their geniculate inputs (Orban et al. 1985). This difference is thought to reflect integrative mechanisms in cortex that effect low-pass filtering (Orban et al. 1985), although inputs from lagged-type LGN cells, which have low temporal resolution (Saul and Humphrey 1990), may account for some of the difference. Whatever the mechanisms for the cortical tuning, they appear either to be resistant to alteration by strobe stimulation or to readjust quickly (within hours?) when cats are moved into natural illumination. We cannot directly address the issue of readjustment, but we note that temporal frequency tuning was not obviously different when cats were tested immediately or many months after removal from the strobe room. Regarding LGN inputs, we show in the following paper (Humphrey et al. 1998) that strobe rearing did not affect the development of lagged cells.

Finally, we note that the strobe effect on direction selectivity is not restricted to area 17 but is observed in a number of cortical and subcortical regions, including area 18 (Kennedy and Orban 1983), the superior colliculus (Flandrin et al. 1976), and the lateral syprasylvian area (Spear et al. 1985 ). We did not examine area 18 , but it is likely that the directional loss there also reflects changes in $\mathrm{S}-\mathrm{T}$ receptivefield structure. This follows simply because S-T structure and direction selectivity are correlated in area 18 (McLean et al. 1994). The loss of directional tuning in the superior colliculus and lateral suprasylvian cortex is probably secondary to changes in areas 17 and 18 because, in normal cats, direction selectivity in these territories is dependent on inputs from primary visual cortex (Rosenquist and Palmer 1971; Spear and Bauman 1979; Wickelgren and Sterling 1969; but cf. Guedes et al. 1983; Mendola and Payne 1993). Thus the strobe-induced changes in S-T structure in primary visual cortex probably have widespread consequences for processing directional information elsewhere in the brain.

Behaviorally, strobe-reared cats show no deficits in the ability to discriminate the direction of moving gratings, provided they are of low spatial frequency and sufficiently high contrast. Pasternak and Leinen (1986) showed that the cats display normal, low-contrast thresholds for detecting whether a grating is moving, but they require contrasts at least 10 times higher than normal to discriminate the direction of motion. Further, at moderate spatial frequencies ( $\geq 0.77$ cycle/deg) they cannot discriminate direction despite being able to spatially resolve stimuli and detect that they are moving. In addition, cats' ability to determine the direction of stimulus motion in the presence of visual noise is greatly reduced by strobe rearing (Pasternak et al. 1990). Together, these studies clearly demonstrate the importance of direction-selective neurons for detecting and discriminating the trajectories of moving objects.

\section{$S$-T receptive-field structure as a mechanism for direction selectivity}

In this section we briefly review evidence linking receptive-field structure to directional tuning in normal cats, summarize two classes of models for direction selectivity that are founded on this link, and consider our data in light of the models.

The general observations that link S-T inseparability to direction selectivity are that 1 ) all $\mathrm{S}$-T inseparable receptive fields are directionally tuned; 2 ) the preferred direction of motion can be predicted from static S-T maps; and 3) all cells lacking direction selectivity are S-T separable. However, considerable heterogeneity exists among neurons in how well directional tuning is predicted by inseparability measures derived from "first-order", 2 S-T maps (Albrecht and Geisler 1991; Reid et al. 1991; Tolhurst and Dean 1991). This heterogeneity partly reflects cells' laminar locations (Murthy et al. 1998). Cells in and adjacent to layer 4 display the most prominent $\mathrm{S}$-T orientation, and a moderate to strong relationship exists between $\mathrm{S}-\mathrm{T}$ structure and direction selectivity. On average, S-T orientation predicts over one-half the observed directional tuning in layer 4 cells. Layer 6 cells, in contrast, uniformly display weak or no first-order S-T orientation despite being as directionally tuned as layer 4 cells.

These laminar differences have implications for models of direction selectivity. We showed (Murthy et al. 1998) that directional tuning in most layer 4 cells can be accounted for by a linear-nonlinear model (i.e., "'exponent model," Albrecht and Geisler 1991; Heeger 1993; Jagadeesh et al. 1997). Here linear S-T summation across an S-T oriented receptive field confers a preferred direction of motion. This preference is then accentuated via a static, power-law amplification of suprathreshold responses, and suppression of subthreshold responses, to produce stronger directional tuning. This exponent model fails to account for strong direction selectivity in layer 6 because cells there lack even moderate first-order S-T orientation. Dynamic nonlinear processes likely predominate in layer 6 .

Insights into the nature of these dynamic nonlinearities, and models generated therefrom, come from second-order $\mathrm{S}$-T maps derived from responses to two bars presented sequentially across the simple-cell receptive field (Emerson and Citron 1992). These maps reveal motion kernels (Emerson and Citron 1992), or interaction functions (Baker and Boulton 1994), that are S-T inseparable. They show that nonlinear facilitatory and/or suppressive interactions are dependent on temporal offsets of responses evoked at different spatial positions. Importantly, the interaction functions accurately predict direction selectivity among cells that are firstorder separable (Emerson and Citron 1989). It is likely that these types of interactions account for directional tuning in layer 6. Overall, this brief review suggests that S-T inseparability, whether revealed in first- or second-order maps, is a critical determinant of direction selectivity.

Our strobe results provide further support for the importance of S-T inseparability. Indeed, for layer 4 cells, they indicate that the fundamental deficit underlying the directional loss is the elimination of first-order inseparability. Without moderate S-T orientation to confer sensitivity to direction, a static amplifying mechanism, envisaged in an exponent-type model (Albrecht and Geisler 1991; Heeger

\footnotetext{
${ }^{2}$ By first-order we mean maps, such as those here, derived from responses to stationary stimuli presented singly.
} 
1993 ), would be incapable of producing direction selectivity.

Our finding of a small strobe-induced reduction in the IIs of layer 6 cells implies some normal contribution of firstorder structure to direction selectivity there. However, that contribution must be very limited, because it grossly underestimates direction tuning (Murthy et al. 1998). Although we have not measured second-order structure, a clear prediction from this work is that the directional deficit in layer 6 reflects a loss of second-order inseparability.

Finally, our results indicate that tonic suppression evoked by motion in the nonpreferred direction does not play a critical role in direction selectivity, at least in layer 4. Such suppression is often envisioned (e.g., Sato et al. 1995) as a nonspecific inhibition that simply raises a cell's threshold to excitatory inputs. It would affect response amplitude but not phase. The fact that the temporal receptive-field structure was markedly altered by strobe rearing indicates that mechanisms other than nonspecific suppression are critical. We will address the issue of mechanisms in the following paper (Humphrey et al. 1998).

\section{Permanence of the changes in direction selectivity and $S$ - $T$ structure}

These results add a new perspective to how altered visual experience early in life can modify neural networks. Previous studies have shown that spatial aspects of neural organization such as those for processing ocular inputs and contour orientation are modifiable during the critical period of development (for reviews, see Daw 1995; Sherman and Spear 1982). Ocular dominance changes such as those induced by monocular lid suture primarily reflect alterations in connectivity that are permanent and that produce enduring amblyopia. Our study reveals that the temporal organization of cells' receptive fields is also developmentally modifiable, and once changes are made they are permanent. Indeed, we were struck by the S-T separability of all simple-cell receptive fields in the two Rochester cats strobe reared $12 \mathrm{yr}$ before our recordings. These animals, labeled 810 and 811 in Pasternak and Leinen (1986), had undergone years of extensive psychophysical testing that required them to make fine directional discriminations. Despite the training, there was no improvement in their visual behavior nor any significant reorganization of their $\mathrm{S}-\mathrm{T}$ receptive-field structure. This implies that strobe rearing caused permanent changes in the inputs to, and connections among, cortical cells. In the following paper (Humphrey et al. 1998) we describe the changes in specific response timings within receptive fields of strobe-reared cats and suggest how alterations in convergence patterns of afferents to cortical cells could give rise to these changes.

We thank P. Baker for computer programming, M. Kieler for electronics support, and J. Feidler for helpful discussions and comments on the manuscript. We are particularly grateful to Dr. Tania Pasternak for kindly providing the first strobe-reared cats used in this study.

This research was supported by National Eye Institute Grants EY-06459 to A. L. Humphrey, EY-10826 to A. B. Saul, and a Core Grant for Vision Research (EY-08098) to the Eye and Ear Institute of Pittsburgh.

Address for reprint requests: A. L. Humphrey, Dept. of Neurobiology, BST E1440, University of Pittsburgh School of Medicine, Pittsburgh, PA 15261.
Received 30 March 1998; accepted in final form 17 August 1998.

\section{REFERENCES}

Albrecht, D. G. And Geisler, W. S. Motion selectivity and the contrastresponse function of simple cells in the visual cortex. Visual Neurosci. 7: 531-546, 1991

BAKer, C. L., JR. AND Boulton, J. C. Neurobiological mechanisms of cortical direction selectivity. In: Computational Vision Based on Neurobiology. SPIE Proceedings, 2054, edited by T. B. Lawton. Bellingham, Washington: SPIE, 1994, p. 104-123.

Cremieux, J., Orban, G. A., Duysens, J., And Amblard, B. Response properties of area 17 neurons in cats reared in stroboscopic illumination. J. Neurophysiol. 57: 1511-1535, 1987.

Cynader, M., Berman, N., AND Hein, A. Cats reared in stroboscopic illumination: effects on receptive fields in visual cortex. Proc. Natl. Acad. Sci. USA 70: 1353-1354, 1973.

Cynader, M. And Chernenko, G. Abolition of directional selectivity in the visual cortex of the cat. Science 193: 504-505, 1976.

Daw, N. W. Visual Development. New York: Plenum, 1995.

DeAngelis, G. C., Ohzawa, I., And Freeman, R. D. Spatiotemporal organization of simple-cell receptive fields in the cat's striate cortex. I. General characteristics and postnatal development. J. Neurophysiol. 69: 10911117, 1993a.

DeAngelis, G. C., Ohzawa, I., And Freeman, R. D. Spatiotemporal organization of simple-cell receptive fields in the cat's striate cortex. II. Linearity of temporal and spatial summation. J. Neurophysiol. 69: 1118$1135,1993 \mathrm{~b}$.

Douglas, R. J. And Martin, K.A.C. A functional microcircuit for cat visual cortex. J. Physiol. (Lond.) 440: 735-769, 1991.

Emerson, R. C. AND Citron, M. C. Linear and nonlinear mechanisms of motion in single neurons of the cat's visual cortex. In: Proceedings of the IEEE International Conference on Systems, Man and Cybernetics, edited by D. L. Kleinman. Cambridge, MA: IEEE, 1989, p. 448-453.

Emerson, R. C. AND Citron, M. C. Linear and nonlinear mechanisms of motion selectivity in simple cells of the cat's striate cortex. In: Nonlinear Vision: Determinants of Neural Receptive Fields, Function and Networks, edited by R. B. Pinter and B. Nabet. Boca Raton, FL: CRC, 1992, p. 75-89.

EySEL, U. T. Lateral inhibitory interactions in areas 17 and 18 of the cat visual cortex. In: Progress in Brain Research. GABA in the Retina and Central Nervous System, edited by R. R. Mize, R. E. Marc and A. M. Sillito. New York: Elsevier, 1992, vol. 90, p. 407-422.

Flandrin, J. M., Kennedy, H., AND AmBlaRD, B. Effects of stroboscopic rearing on binocularity and directionality of cat superior colliculus neurons. Brain Res. 101: 576-581, 1976.

Guedes, R., Watanabe, S., And Creutzfeldt, O. D. Functional role of association fibres for a visual association area: the posterior suprasylvian sulcus of the cat. Exp. Brain Res. 49: 13-27, 1983.

HeEger, D. J. Modeling simple-cell direction selectivity with normalized, half-squared, linear operators. J. Neurophysiol. 70: 1885-1898, 1993.

Hubel, D. H. AND Wiesel, T. N. Receptive fields, binocular interaction and functional architecture in the cat's visual cortex. J. Physiol. (Lond.) 160: 106-154, 1962.

Humphrey, A. L. AND SAul, A. B. Strobe rearing alters the spatiotemporal structure of simple cell receptive fields in cat area 17. Soc. Neurosci. Abstr. 21: 1648, 1995.

Humphrey, A. L., Saul, A. B., AND Feidler, J. C. Strobe rearing prevents the convergence of inputs with different response timings onto area 17 simple cells. J. Neurophysiol. 80: 3005-3020, 1998.

Humphrey, A. L., Sur, M., Uhlrich, D. J., AND Sherman, S. M. Projection patterns of individual $\mathrm{X}$ - and $\mathrm{Y}$-cells axons from the lateral geniculate nucleus to cortical area 17 in the cat. J. Comp. Neurol. 233: 159-189, 1985.

Humphrey, A. L. AND Weller, R. E. Functionally distinct groups of Xcells in the lateral geniculate nucleus of the cat. J. Comp. Neurol. 268: 429-447, 1988a.

Humphrey, A. L. AND Weller, R. E. Structural correlates of functionally distinct X-cells in the lateral geniculate nucleus of the cat. J. Comp. Neurol. 268: 448-468, 1988 b.

Jagadeesh, B., Wheat, H. S., Kontsevich, L. L., Tyler, C. W., and FersTER, D. Direction selectivity of synaptic potentials in simple cells of the cat visual cortex. J. Neurophysiol. 78: 2772-2789, 1997.

Jones, J. P. AND PALMER, L. A. The two-dimensional spatial structure of 
simple receptive-fields in cat striate cortex. J. Neurophysiol. 58: 11871211, 1987.

Kennedy, H. And Orban, G. A. Response properties of visual cortical neurons in cats reared in stroboscopic illumination. J. Neurophysiol. 49: 686-704, 1983.

MaEX, R. AND ORban, G. A. Model circuit of spiking neurons generating directional selectivity in simple cells. J. Neurophysiol. 75: 1515-1545, 1996.

McLean, J. and Palmer, L. A. Contribution of linear spatiotemporal receptive field structure to velocity selectivity of simple cells in area 17 of cat. Vision Res. 29: 675-679, 1989.

McLean, J., RaAB, S., AND PALMer, L. A. Contribution of linear mechanisms to the specification of local motion by simple cells in areas 17 and 18 of the cat. Visual Neurosci. 11: 271-294, 1994.

Mendola, J. D. And Payne, B. R. Direction selectivity and physiological compensation in the superior colliculus following removal of areas 17 and 18. Visual Neurosci. 10: 1019-1026, 1993.

Movshon, J. A., Thompson, I. D., And Tolhurst, D. J. Spatial summation in the receptive fields of simple cells in the cat's striate cortex. J. Physiol. (Lond.) 283: 53-77, 1978.

Murthy, A., Humphrey, A. L., Saul, A. B., And Feidler, J. C. Laminar differences in the spatiotemporal structure of simple cell receptive fields in cat area 17. Visual Neurosci. 15: 239-256, 1998.

O'Leary, J. L. Structure of the area striata of the cat. J. Comp. Neurol. 75: 131-164, 1941.

Olson, C. R. And Pettigrew, J. D. Single units in visual cortex of kittens reared in stroboscopic illumination. Brain Res. 70: 189-204, 1974.

Orban, G. A., Hoffmann, K.-P., And DuYsens, J. Velocity selectivity in the cat visual system. I. Responses of LGN cells to moving bar stimuli: a comparison with cortical areas 17 and 18. J. Neurophysiol. 54: 10261049, 1985.

Pasternak, T., Albano, J. E., and Harvitt, D. M. The role of directionally selective neurons in the perception of global motion. J. Neurosci. 10: 3079-3086, 1990.

Pasternak, T. and Leinen, L. J. Pattern and motion vision in cats with selective loss of cortical direction selectivity. J. Neurosci. 6: 938-945, 1986.

Pasternak, T., Schumer, R. A., Gizzi, M. S., And Movshon, J. A. Abolition of visual cortical direction selectivity affects visual behavior in cats. Exp. Brain Res. 61: 214-217, 1985.

Reid, R. C., Soodak, R. E., and Shapley, R. M. Linear mechanisms of directional selectivity in simple cells of cat striate cortex. Proc. Natl. Acad. Sci. USA 84: 8740-8744, 1987.

ReID, R. C., Soodak, R. E., and Shapley, R. M. Directional selectivity and spatiotemporal structure of receptive fields of simple cells in cat striate cortex. J. Neurophysiol. 66: 505-529, 1991.

Rosenquist, A. C. AND PALMER, L. A. Visual receptive field properties of cells of the superior colliculus after cortical lesions in the cat. Exp. Neurol. 33: 629-652, 1971.

SAUL, A. B. AND HumPHREY, A. L. Spatial and temporal response properties of lagged and nonlagged cells in the cat lateral geniculate nucleus. $J$. Neurophysiol. 64: 206-224, 1990.

Saul, A. B. AND Humphrey, A. L. Evidence of input from lagged cells in the lateral geniculate nucleus to simple cells in cortical area 17 of the cat. J. Neurophysiol. 68: 1190-1207, 1992a.

SAUL, A. B. AND Humphrey, A. L. Temporal frequency tuning of direction selectivity in cat visual cortex. Visual Neurosci. 8: 365-372, 1992b.

SAUl, A. B. AND Humphrey, A. L. Spatiotemporal receptive field structure in strobe-reared cats. Assoc. Res. Vis. Ophthalmol. (Suppl.) 15: 1468, 1994.

Sato, H., Katsuyama, N., Tamura, H., Hata, Y., and Tsumoto, T. Mechanisms underlying direction selectivity of neurons in the primary cortex of the macaque. J. Neurophysiol. 74: 1382-1394, 1995.

Sherman, S. M. AND SPEAR, P. D. Organization of visual pathways in normal and visually deprived cats. Physiol. Rev. 62: 738-855, 1982.

SiLlito, A. M. Inhibitory processes underlying the directional specificity of simple, complex, and hypercomplex cells in the cat's visual cortex. J. Physiol. (Lond.) 271: 775-785, 1977.

SiLlito, A. M. Functional considerations of the operation of GABAergic inhibitory processes in the visual cortex. In: Cerebral Cortex, edited by E. G. Jones and A. Peters. New York: Plenum, 1984, vol. 2, p. 91-117.

Skottun, B. C., DeValois, R. L., Grosof, D. H., Movshon, J. A., AlBRECHT, D. G., AND Bonds, A. B. Classifying simple and complex cells on the basis of response modulation. Vision Res. 31: 1079-1086, 1991.

SPEAR, P. D. AND BAumanN, T. P. Effects of visual cortex removal on receptive-field properties of neurons in lateral suprasylvian visual area of the cat. J. Neurophysiol. 42: 31-56, 1979.

Spear, P. D., Tong, L., McCall, M. A., And Pasternak, T. Developmentally induced loss of direction selective neurons in cat lateral suprasylvian visual cortex. Dev. Brain Res. 20: 281-285, 1985.

Suarez, H., Кoch, C., ANd Douglas, R. Modeling direction selectivity of simple cells in striate visual cortex within the framework of the canonical microcircuit. J. Neurosci. 15: 6700-6719, 1995.

Tolhurst, D. J. AND DEAN, A. F. Evaluation of a linear model of directional selectivity in simple cells of the cat's striate cortex. Visual Neurosci. 6: 421-428, 1991.

Wickelgren, B. G. AND Sterling, P. Influence of visual cortex on receptive fields in the superior colliculus of the cat. J. Neurophysiol. 32: $16-23,1969$. 